\title{
FLUID DYNAMIC VIBRATION ABSORBER FOR CABIN SUSPENSION
}

\author{
Nicolas Brötz*, Manuel Rexer, Peter F. Pelz \\ Institut für Fluidsystemtechnik, Technische Universität Darmstadt, Otto-Berndt-Straße 2, 64287 Darmstadt \\ * Corresponding author: Tel.: +49 6151 1627126; E-mail address: nicolas.broetz@fst.tu-darmstadt.de
}

\begin{abstract}
Truck drivers spend all day moving goods. They are exposed to vibrations every time they drive. Modern cabin suspension and an air-suspended seat already offer a high level of comfort. This, however, is designed for vertical dynamics and you can observe the cab of a truck performs large pitching vibrations during acceleration. These are examined here. A pitch model of the cabin is set up for this purpose. On the basis of this model it is examined which reduction of the vibration can be achieved by the use of a hydraulically translated vibration absorber. The advantage of this absorber is the use of the hydraulic transmission to reduce the heavy mass at high absorber inertia. $4 \mathrm{~kg}$ of fluid mass act as $131 \mathrm{~kg}$ absorber mass reducing vibrations by more than $10 \%$. The conventional vibration absorber is inacceptable due to the additional load. The investigation based on VDI 2057 Part 1 shows that driving comfort can be increased.
\end{abstract}

Keywords: fludi dynamic vibration absorber, cabin suspension, vibration, health protection, lightweight design

\section{INTRODUCTION}

Half a million professional drivers are transporting goods in Germany. Driving comfort is essential for health protection. Hence, airsuspended seats [1] are already part of everyday life. Vertical dynamics of the truck cabin are mastered by isolation $[2,3]$. Also active systems for the improvement of vertical dynamics are investigated by several studies $[4,5]$.

The situation is less satisfying with pitch dynamics. Due to the soft suspension of the cabin and its high inertia, pitch oscillations are dominant during acceleration and breaking.

The Fluid Dynamic Vibration Absorber developed within the DFG (Deutsche Forschungs Gemeinschaft) Collaborative Research Centre 805 "Control of uncertainty in load carrying structures in mechanical engineering", reduces pitch oscillations. By reducing the pitch oscillations, the exposure to the driver is reduced. In this paper, the exposure reduction achieved by the use of the Fluid Dynamic Vibration Absorber (FDVA) is evaluated with the aid of VDI 2057 Part 1 [6].

\section{FLUID DYNAMIC VIBRATION ABSORBER}

An absorber is used to reduce vibrations from an oscillating system. A conventional dynamic vibration absorber consists of a heavy mass and a capacity. In comparison to a conventional dynamic vibration absorber, that is not in the sense of lightweight construction due to the additional mass, the Fluid Dynamic Vibration Absorber (FDVA) reduces the dynamic mass by the use of hydrostatic transmission [7]. The movement of the cabin's suspension $z_{S}$ directs the force via the absorber spring to the piston of the FDVA. The piston with area $A$ pumps oil from one chamber through a duct to the other chamber. Figure $\mathbf{1}$ shows the functional demonstrator. A first validation of the model [8] could already be shown with the functional demonstrator $[9,10]$. The ratio $\alpha=A / a$ describes the ratio between piston $A$ and channel cross section $a$. Due to the piston movement the fluid mass inside the ducts is accelerated $\alpha$-times the piston acceleration caused by the hydraulic transmission. This translation produces the virtual tilting mass. 


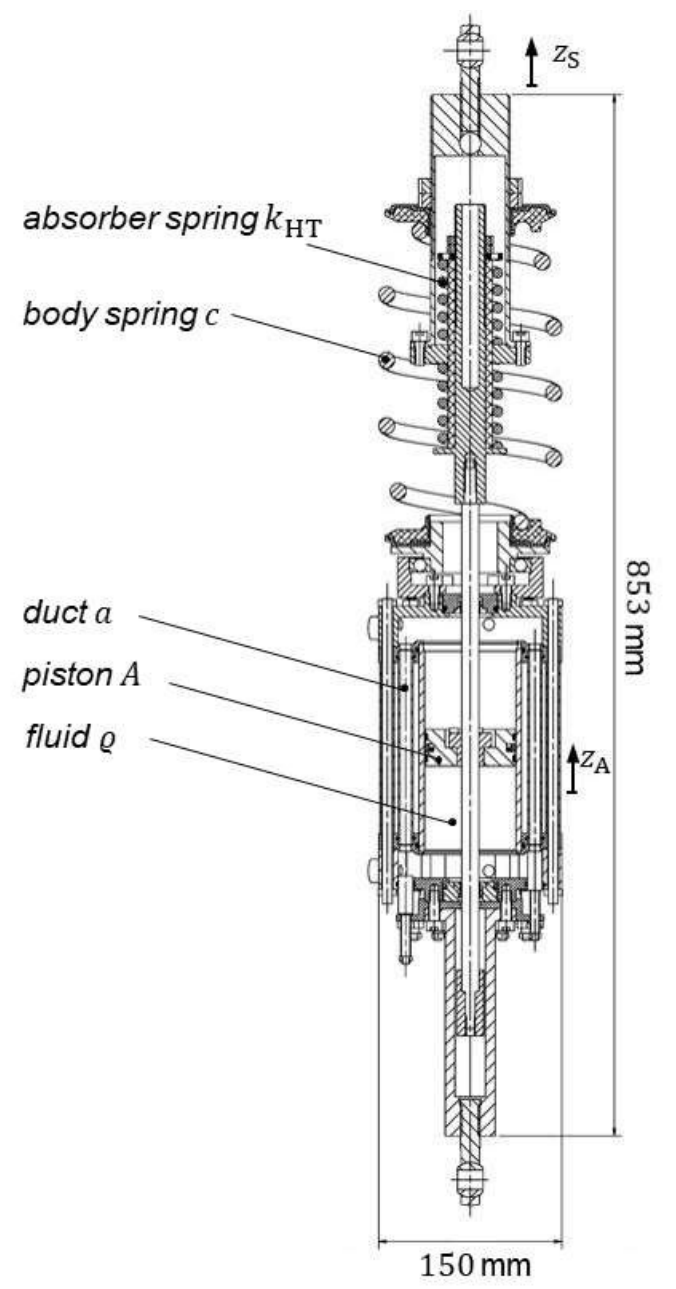

Figure 1: Functional demonstrator of FDVA [9]

The FDVA force $F_{H T}=k_{\mathrm{HT}}\left(z_{\mathrm{S}}-z_{\mathrm{A}}\right)$ is described by the equation of motion

$\left[m_{\mathrm{P}}+\left(2 \alpha \beta+\alpha^{2}\right) m_{\mathrm{F}}\right] \ddot{z}_{\mathrm{A}}=k_{\mathrm{HT}}\left(z_{\mathrm{S}}-z_{\mathrm{A}}\right)+$ $p_{\mathrm{L}} A$

with the piston mass $m_{\mathrm{P}}$, the ratio between cylinder length and duct length $\beta$, the absorber stiffness $k_{\mathrm{HT}}$ and the pressure loss $p_{\mathrm{L}}$. The fluid mass $m_{F}$ is equal to the fluid in the duct. It becomes obvious from the equation of motion that this mass is translated. When we compare the measurement results for transmissibility $V=$ $\hat{z}_{\mathrm{A}} / \hat{z}_{\mathrm{S}}$, phase $\psi=-\arg \left(\hat{z}_{\mathrm{A}} / \hat{z}_{\mathrm{S}}\right)$ and FDVA force $F_{H T}$ (Figure 2) with the simulation model they are in good agreement. Small differences in the absorber force $F_{H T}$ appear because friction is linearized.
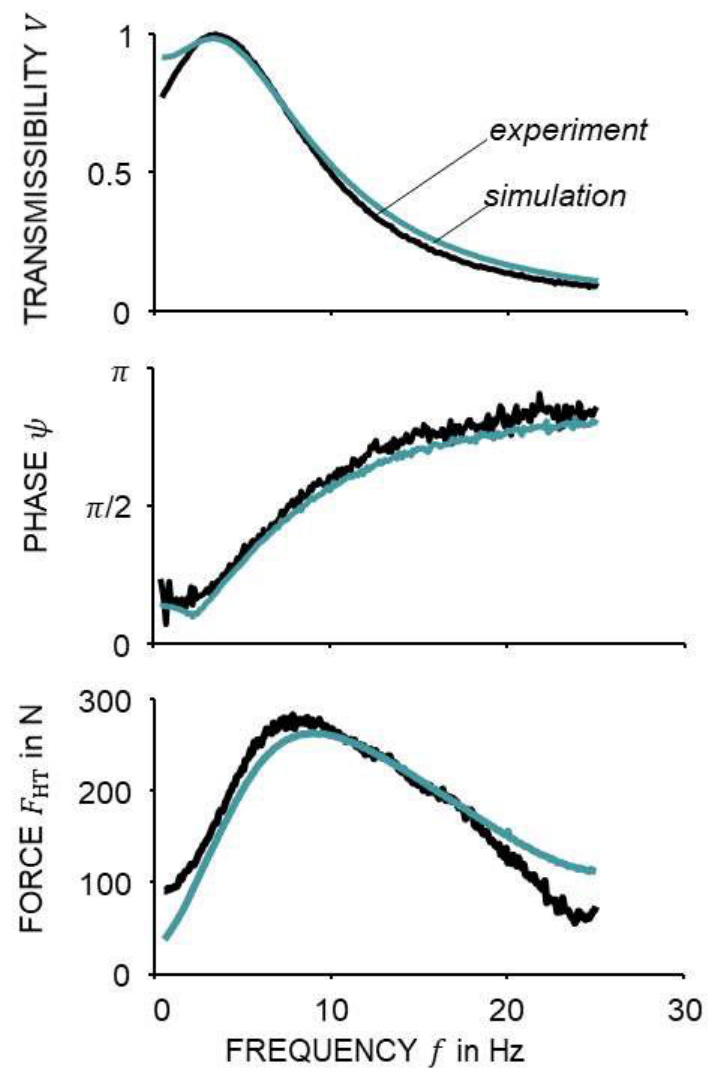

Figure 2: Measurement and simulation of FDVA with spring stiffness $57.4 \mathrm{~N} / \mathrm{mm}$ and 2 opened ducts at $4 \mathrm{~mm}$ excitation

We use the validated FDVA model for the following calculations and optimize the parameters for an adoption to a cabin suspension.

\section{CABIN SUSPENSION}

The cabin of a truck (Figure 3 ) is mounted on the front and rear with spring dampers on the chassis. The front suspension is designed to turn the entire cab for access to the engine.

There are many eigenfrequencies of the truck due to the flexibly mounted motor, the wheel suspension and the trailer vibrations [11]. A model is used to analyse the systems vibration reduction (Figure 4).

The rotating behaviour around the front suspension point can be assumed as an approximation.

The rotatory vibration behaviour around the front suspension is described by the equation of motion. 


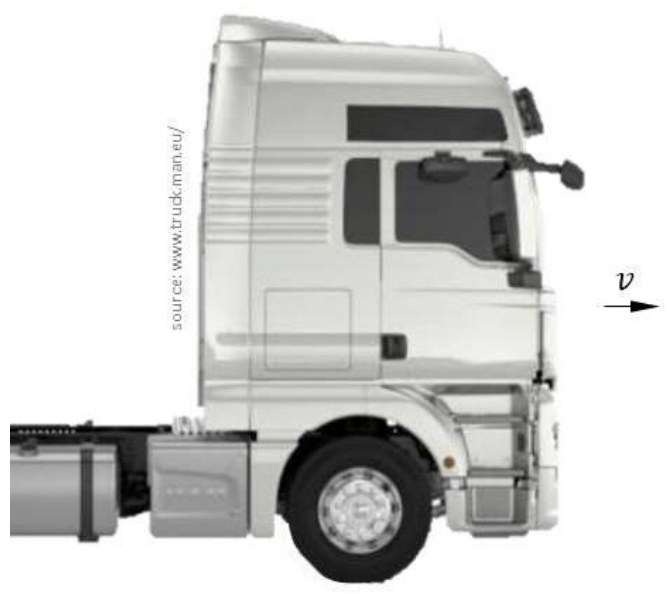

Figure 3: Truck cabin [12]

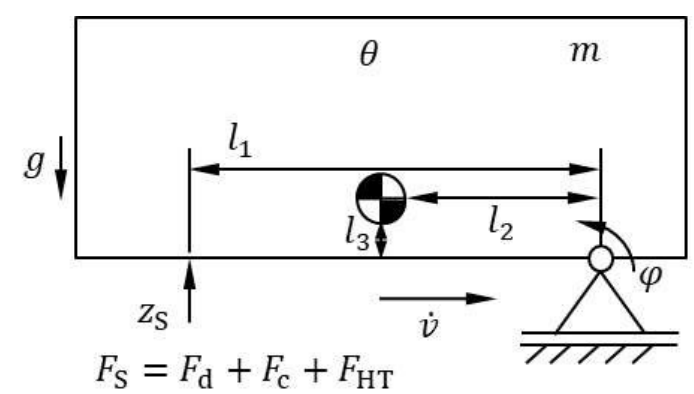

Figure 4: Simplified cabin model

The equation of motion for the simplified cabin model is given by:

$$
\begin{aligned}
\theta \ddot{\varphi}= & -\sqrt{l_{2}^{2}+l_{3}^{2}} m \dot{v} \sin \left(\varphi+\varphi_{0}\right)- \\
& \sqrt{l_{2}^{2}+l_{3}^{2}} m g \cos \left(\varphi+\varphi_{0}\right)- \\
& l_{1}^{2}(\varphi k+\dot{\varphi} d)-l_{1} F_{\mathrm{HT}} .
\end{aligned}
$$

The dimensions of the cabin were taken from the manufacturer's data sheet [12]. The other characteristic values were taken from [13] and largely correspond to the values of a $\mathrm{ZF}$ test vehicle. Since the model of the cabin is kept very simple, the demand on the accuracy of the parameters is also not very high. Table 1 shows the parameters used.

Table 1: Parameters of truck cabin $[12,13]$

\begin{tabular}{ll}
\hline Cabin parameter & Value \\
\hline Half cabin mass $m$ & $650 \mathrm{~kg}$ \\
Length $l_{1}$ & $2 \mathrm{~m}$ \\
Length $l_{2}$ & $1 \mathrm{~m}$ \\
Length $l_{3}$ & $1 \mathrm{~m}$ \\
Suspension stiffness $c$ & $40000 \mathrm{~N} / \mathrm{m}$ \\
Damping constant $d$ & $13300 \mathrm{Ns} / \mathrm{m}$ \\
Gravitation constant $g$ & $9.81 \mathrm{~m} / \mathrm{s}$ \\
\hline
\end{tabular}

The measured velocity profile shown in Figure 5 is used for the investigation.

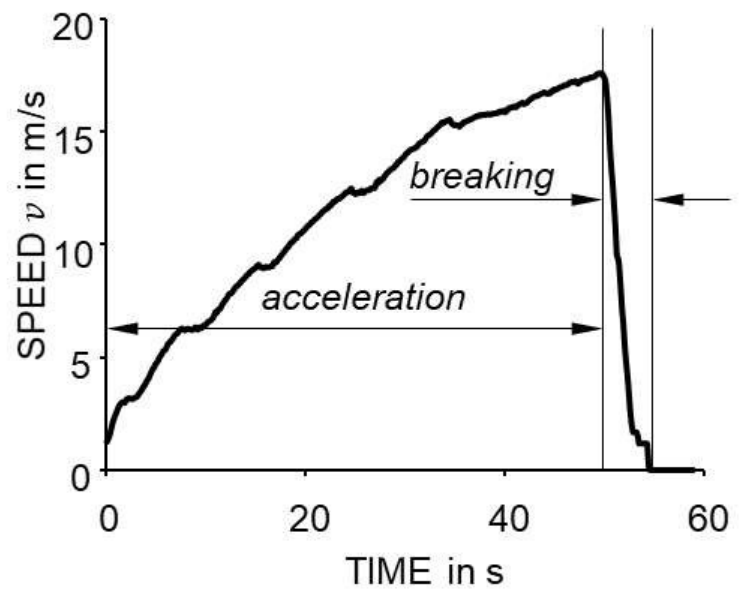

Figure 5: Speed profile

This profile originates from a test run by $\mathrm{ZF}$ Friedrichshafen to investigate lightweight components [14]. It represents an acceleration with gearshifts and a braking action. By changing the speed, the cabin is set in rotation.

If one compares the deflection of the rear damper between the simplified model and the evaluation of the measurement run in Figure 6, a good agreement can be seen, although the vertical dynamics were disregarded in the model. The maximum deflection of the real system was not taken into account in the model and shows a difference in the braking process.

The model will be used for further investigations to estimate the potential of the FDVA application.

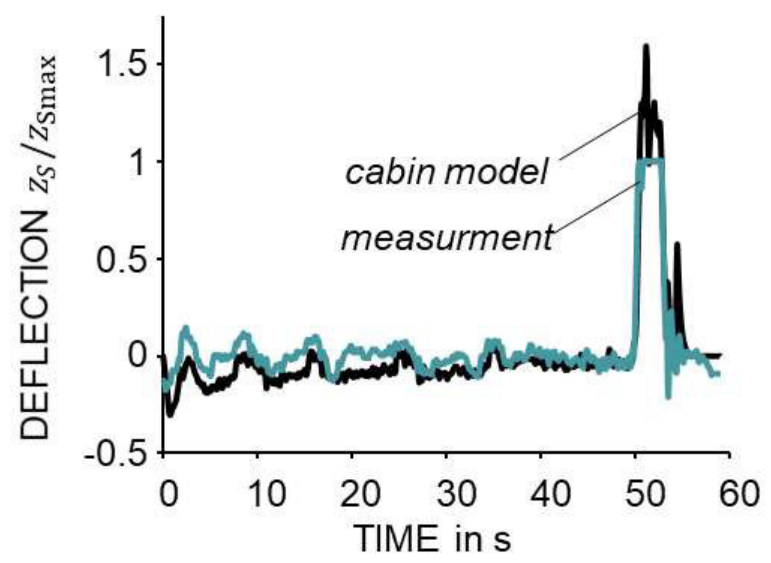

Figure 6: Comparison between simplified model and measurement 


\section{FDVA DESIGN}

A vibration absorber absorbs the vibration energy of a vibrating system. Therefore, the energy is transferred from the vibrating system to the vibration absorber. For this purpose, a capacity with an inertia is added to the system [15]. The inertia is usually at least an order of magnitude smaller than the inertia of the system in order not to unnecessarily increase the total weight. It shows the advantage of the FDVA. The FDVA achieves a much higher inertia with a small additional mass. The optimal design of the FDVA is given by the tuning of the absorber frequency. The optimal eigenfrequency of the FDVA

$f_{\mathrm{A}}=f_{\mathrm{S}} \frac{1}{\sqrt{1-\mu}}$

is close to the systems eigenfrequency $f_{S}$, but is still dependent on the ratio $\mu=m_{\mathrm{A}} / m_{\mathrm{S}}$ between the tilting mass $m_{\mathrm{A}}$ and the system mass $m_{S}$. The frequency response always cuts two points for a variation of damping. We get the optimum eigenfrequency if these two points have the same ordinate value [15]. The damping depends on the transmission ratio. Taking these considerations into account, the tuning parameters of the FDVA can be given in Table 2.

Table 2: Parameters of FDVA design

\begin{tabular}{ll}
\hline Cabin parameter & Value \\
\hline Oil mass $m_{\text {oil }}$ & $3.71 \mathrm{~kg}$ \\
Tilting mass $m_{\mathrm{A}}$ & $131.04 \mathrm{~kg}$ \\
Eigenfrequency $f_{\mathrm{A}}$ & $1.8 \mathrm{~Hz}$ \\
Ratio $\alpha$ & 48 \\
\hline
\end{tabular}

\section{SIMULATION RESULT}

The equations of motion are transformed into a first order form and solved using the Runge-Kutta method. The input is defined as the speed of the truck. The angular acceleration of the cabin represents the result (Figure 7).

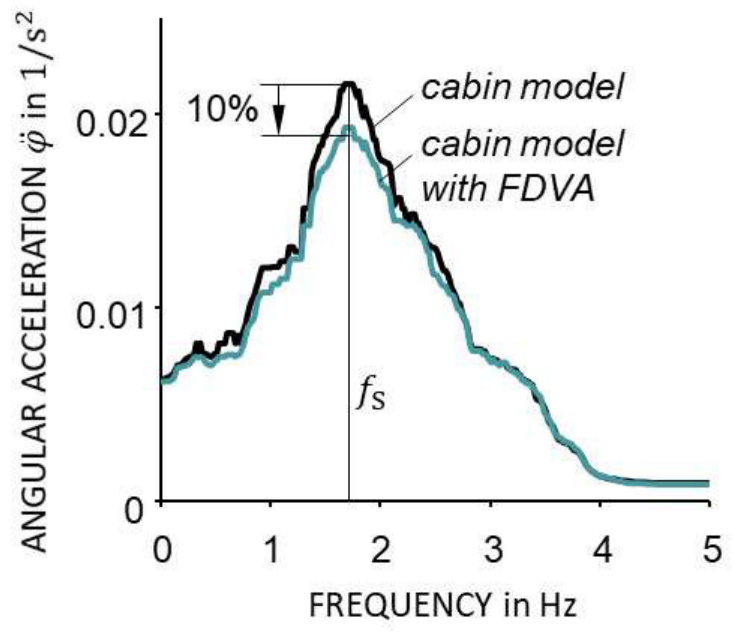

Figure 7: Comparison of angular acceleration between cabin model with and without FDVA

The frequency range of angular acceleration from 0 to $5 \mathrm{~Hz}$ is plotted. At higher frequencies the amplitude of angular acceleration is very small and has hardly any influence on the driver. It can be seen that using the FDVA reduces the amplitude by about $10 \%$ in the range around the eigenfrequency.

\section{EVALUATION OF THE IMPACT ON THE DRIVER}

In the following, the effects of angular acceleration on well-being and physical health risk will be investigated. There are regulations that limit the time exposure of humans to vibration through the Ordinance on the Protection of Employees from Noise and Vibration Hazards [16].

The type, extent and duration of exposure shall be assessed. In the case examined here it concerns rotatory oscillations on a seated person which are evaluated in accordance to VDI 2057 Part 1 [6]. Accordingly, the rotation on the seat is weighted with the frequency weighting $W_{\mathrm{e}}$ (Figure 8). 


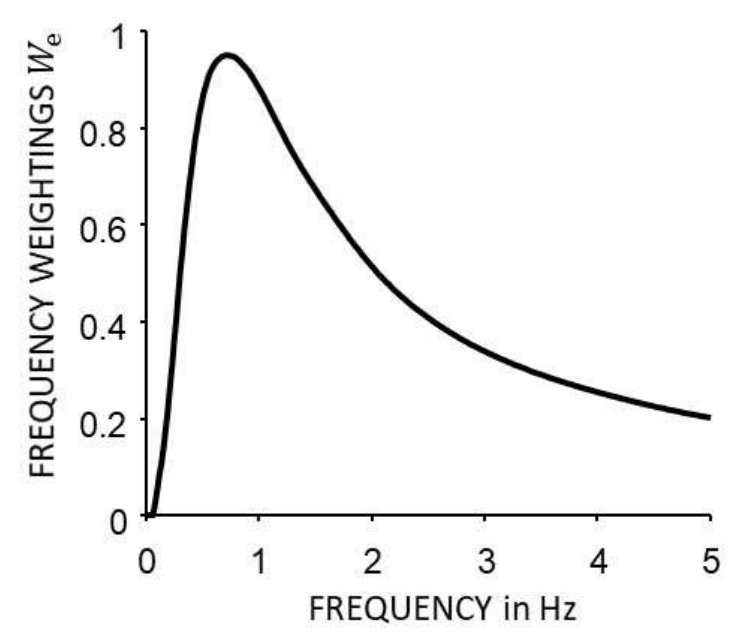

Figure 8: Frequency weightings $W_{\mathrm{e}}$ for a rotation on the seat according to VDI 2057 part 1

The acceleration evaluation of the nodding cabin on the driver in sitting position reflects the wellbeing. The driver therefore feels the worst at a frequency of $0.8 \mathrm{~Hz}$.

From the determined partial frequency weightings

$a_{\mathrm{wl}, \mathrm{n}}=W_{\mathrm{e}} a_{\mathrm{n}}$

the effective value of the frequency-weighted acceleration of the entire spectrum

$a_{\mathrm{wl}}=\sqrt{\sum_{n=1}^{m} a_{\mathrm{wl}, \mathrm{n}}^{2}}$

is calculated.

For the cabin model with FDVA a value of $0.059 \mathrm{rad} / \mathrm{s}^{2}$ is obtained compared to the result without FDVA with $0.064 \mathrm{rad} / \mathrm{s}^{2}$. This value is multiplied by the weighting factor $k_{1}=0.4 \mathrm{~m} / \mathrm{rad}$ from ISO 2631 Part 1 [17] to convert the value into a linear comparison value. For the assessment acceleration, which is compared with the limit value, the effective value $a_{\mathrm{wl}}$ must still be scaled with the action duration $T$ as follows:

$a_{\mathrm{W} 8 l}=k_{\mathrm{l}} \cdot a_{\mathrm{wl}} \cdot \sqrt{\frac{T}{T_{0}}}$.

The exposure time $\mathrm{T}$ is set in relation to the assessment duration of the working day $T_{0}=8 \mathrm{~h}$. Assuming a $2 \mathrm{~h}$ ride in stop and go, $T=2 \mathrm{~h}$ can be set, as there is constant acceleration and braking during stop and go. This approximately corresponds to the speed profile shown in figure 4. These two hours do not come close to a potential health risk. With a value of $a_{\mathrm{W} 81}=$ 0.0126 for the cabin model without FDVA, the assessment acceleration is still an order of magnitude below a potential health risk for which the limit values are shown in Figure 9. So even with a full 8 hours of traffic jam no health risk is to be expected here.

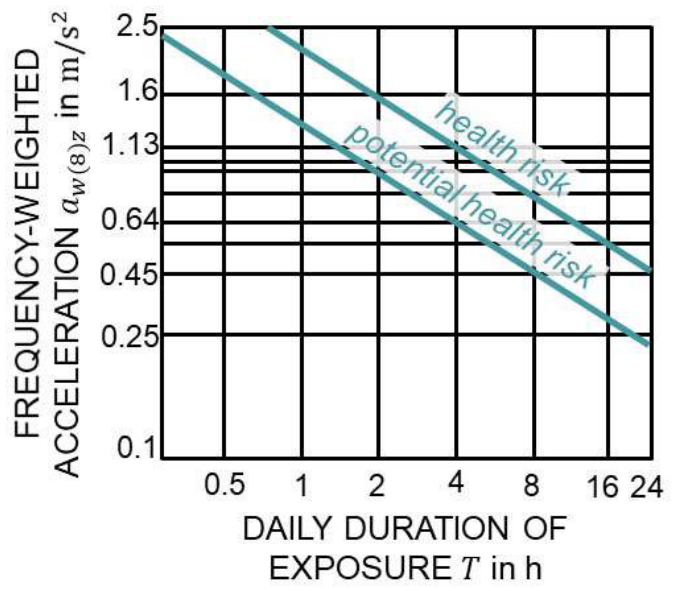

Figure 9: Area of increased health risk by stimulation [6]

However, this result is not surprising for an existing truck. The truck is designed to not expose the driver to any health risk during the journey. Even if there is no health risk, a good driving comfort is a sales argument. In addition to the health risk, the driver's perception can also be evaluated. The effective value with the weighting factor $k_{\mathrm{l}}$ is used for this evaluation. The perception is perceived as described in Table 3 . The greater the acceleration value, the stronger the perception. The perception of angular acceleration with an acceleration value $a_{\mathrm{wl}}=$ $0.0256 \mathrm{~m} / \mathrm{s}^{2}$ related to linear movements in cabin suspension without FDVA is evaluated as easily perceptible according to Table 3 . With FDVA $a_{\mathrm{wl}}=0.0236 \mathrm{~m} / \mathrm{s}^{2}$ and moves towards barely percentible, which improves comfort.

Table 3: Scale of subjective perception [6]

\begin{tabular}{ll}
\hline $\begin{array}{l}\text { Root-mean-square values } a_{\mathrm{wl}} \\
\text { of the frequency weighted } \\
\text { acceleration in } \mathrm{m} / \mathrm{s}^{2}\end{array}$ & $\begin{array}{l}\text { Description of } \\
\text { perception }\end{array}$ \\
\hline$<0.01$ & not perceptible \\
0.015 & threshold of perception \\
$0.015-0.02$ & barely perceptible \\
$0.02-0.08$ & easily perceptible \\
$0.08-0.315$ & strongly perceptible \\
$>0.315$ & extremely perceptible \\
\hline
\end{tabular}

A reduction of the pitch oscillation to a barely perceptible sensation is therefore desirable. 


\section{CONCLUSION}

We investigated the effect of pitch vibrations on the driver of a truck and how they can be reduced with a new type of vibration absorber. For this purpose, a simple cabin model for pitch oscillation was set up, which is excited by the acceleration of the truck in longitudinal direction. The comparison of the deflection of the rear suspension between model and measurement shows a good approximation. With this the effects of the pitch vibrations on the driver are investigated and compared between a model with and without integrated hydraulically translated vibration absorber. The simulation model of the Fluid Dynamic Vibration Absorber was validated and adopted to the cabin suspension. In the eigenfrequency of the cabin, about $1.8 \mathrm{~Hz}$, the amplitude can be reduced by $10 \%$ with only $4 \mathrm{~kg}$ additional mass. This is possible by the hydraulic transmission of the vibration absorber.

Driving comfort rated by the oscillation sensation is classified as easily perceptible. This easy perceptibility reduces the comfort and it is desirable to reduce the oscillations. Thus, a cabin suspension is a possible application for the FDVA. With this knowledge, the next step is to use the model of the FDVA in the half-vehicle truck model. This will show the FDVA's influence on the other eigenfrequencies of the truck.

\section{ACKNOWLEDGMENT}

Funded by the Deutsche Forschungsgemeinschaft (DFG, German Research Foundation) - Projektnummer 57157498 - SFB 805 . The authors especially would like to thank the project cooperation partner ZF Friedrichshafen AG for supporting this project.

\section{NOMENCLATURE}

$\begin{array}{ll}a & \text { Duct surface } \\ a_{\mathrm{n}} & \text { Partial acceleration amplitudes } \\ A & \text { Piston surface } \\ a_{\mathrm{W} 8 \mathrm{l}} & \text { Evaluation acceleration } \\ a_{\mathrm{wl}} & \begin{array}{l}\text { Root-mean-square value of the frequency- } \\ \text { weighted acceleration }\end{array} \\ a_{\mathrm{wl}, \mathrm{n}} & \begin{array}{l}\text { Partial } \\ c\end{array} \\ d & \text { Suspension stiffness } \\ f_{\mathrm{A}} & \text { Damping constant } \\ f_{\mathrm{S}} & \text { Eigenfrequency of the FDVA } \\ \end{array}$

$F_{\mathrm{HT}} \quad$ Force of FDVA

FDVA Fluid Dynamic Vibration Absorber

$g \quad$ Gravitation constant

IFK International Conference of Fluid Power

$k_{\mathrm{l}} \quad$ Correction factor for assessment quantities

$k_{\mathrm{HT}} \quad$ Absorber stiffness

$l_{1} \quad$ Distance between front and rear suspension

$l_{2} \quad$ Distance between front suspension and centre of mass in longitudinal direction

$l_{3} \quad$ Distance between front suspension and centre of mass in vertical direction

$m \quad$ Half cabin mass

$m_{\mathrm{A}} \quad$ Tilting mass

$m_{\mathrm{F}} \quad$ Fluid mass in duct of FDVA

$m_{\text {oil }}$ Oil mass of FDVA

$m_{\mathrm{P}} \quad$ Piston mass

$m_{\mathrm{S}} \quad$ Mass of oscillating System

$p_{\mathrm{L}} \quad$ Pressure loss

$T \quad$ Exposure duration

$T_{0} \quad$ Assessment duration

$v \quad$ Truck speed

$V \quad$ Transmissibility

$W_{\mathrm{e}} \quad$ Frequency weightings

$z_{A} \quad$ Absorber motion

$Z_{S} \quad$ System motion

$\alpha \quad$ Ratio between piston surface and duct surface

$\beta \quad$ Ratio between cylinder length and duct length

$\theta \quad$ Rotational inertia of truck cabin

$\theta_{\mathrm{A}} \quad$ Inertia of FDVA

$\mu \quad$ Ratio between tilting and system mass

@ Oil density

$\varphi \quad$ Pitch angle

$\dot{\varphi} \quad$ Angular velocity

$\ddot{\varphi} \quad$ Angular acceleration

$\varphi_{0} \quad$ Starting pitch angle

$\psi \quad$ Phase shift

\section{REFERENCES}

[1] Choi SB, Choi JH, Lee YS, Han MS (2003) Vibration Control of an ER Seat Suspension for a Commercial Vehicle. J. Dyn. Sys., Meas., Control 125(1):60-68.

[2] Tong RT, Amirouche F (1998) Truck cab suspension design: optimisation and vibration control International Journal of Heavy Vehicle Systems, Bd 5. Inderscience, S 236-260

[3] Appel W, Hoepke E, Breuer S (2013) Nutzfahrzeugtechnik. Grundlagen, Systeme, Komponenten, 7. Aufl. Praxis: Kraftfahrzeugtechnik. Vieweg + Teubner, Wiesbaden

[4] Evers W-J, Besselink I, Teerhuis A, Nijmeijer H (2011) On the achievable performance using 
variable geometry active secondary suspension systems in commercial vehicles. Vehicle System Dynamics 49(10):1553-1573.

[5] Evers WJE (2010) Improving driver comfort in commercial vehicles. Modeling and control of a low-power active cabin suspension system

[6] Verein Deutscher Ingenieure (2017) Einwirkung mechanischer Schwingungen auf den Menschen. Ganzkörperschwingungen, 3. Aufl 13.160(VDI 2057 Blatt 1)

[7] Pelz PF, Cloos FJ, Corneli T., Hedrich P, Nakhjiri M. (2015) Leichtbautilger für Fahrwerke $3 . \quad$ VDI-Fachtagung Schwingungsdämpfung, Bd 2261. VDI-Verlag, Leonberg, S 121-129

[8] Corneli T, Pelz PF (2014) Employing Hydraulic Transmission for Light Weight Dynamic Absorber. In: Murrenhoff $\mathrm{H}$ (Hrsg) 9th International Fluid Power Conference (9th IFK), Vol. 3. HP - Fördervereinigung Fluidtechnik, Aachen, S 198-209

[9] Brötz N, Hedrich P, Pelz PF (2018) Integrated Fluid Dynamic Vibration Absorber for Mobile Applications. In: Murrenhoff H (Hrsg) 11th International Fluid Power Conference (11th IFK), 11. Aufl, Vol. 1. RWTH Aachen University, Aachen, S 14-25

[10] Brötz N, Pelz PF (2020) Bayesian Uncertainty Quantification in the Development of a New Vibration Absorber Technology. Proceedings of IMAC 2020: submitted
[11] Zhang J, Guo P, Lin J, Wang K (2016) A mathematical model for coupled vibration system of road vehicle and coupling effect analysis. Applied Mathematical Modelling 40(2):1199-1217.

[12] MAN MAN TGX - Fahrerhaus für den Fernverkehr.

http://man.etpl.ch/truck/global/de/fernverkehr/t gx/fahrerhaus/fahrerhaus-xxl/Fahrerhaus-

XXL.html. Zugegriffen: 11. November 2019

[13] Evers WJE, Besselink IJM, Teerhuis AP, Oomen TAE, Nijmeijer H Experimental Validation of a Quarter Truck Model Using Asynchronous Measurements with Low Signal-to-Noise Ratios

[14] Heimann J, Müller I, Neu A, Stieglitz A (2019) CLFT - Leichtbau für den schweren Lkw. Lightweight Des 12(1):46-51

[15] Den Hartog JP (1985) Mechanical vibrations. Dover books on engineering. Dover Publications, New York

[16] Bundesministerium der Justiz und für Verbraucherschutz (2007) Verordnung zum Schutz der Beschäftigten vor Gefährdungen durch Lärm und Vibrationen. Lärm- und Vibrations-Arbeitsschutzverordnung LärmVibrationsArbSchV

[17] Internatinal Organization for Standardization (1997) Mechanical vibration and shok. Evaluation of human exposure to whole-body vibration. ISO 2631-1:1997, Switzerland 